\title{
Blood Glucose Level and HbA1C in Pediatric Patients with Diabetes Mellitus Type 1
}

\author{
Anisha Sefina Priatna, ${ }^{1}$ R.M.Ryadi Fadil, ${ }^{2}$ Nugroho Harry Susanto ${ }^{3}$ \\ ${ }^{1}$ Faculty of Medicine Universitas Padjadjaran, ${ }^{2}$ Department of Child Health Faculty of Medicine \\ Universitas Padjadjaran/Dr. Hasan Sadikin General Hospital, Bandung, ${ }^{3}$ Department of Public \\ Health Faculty of Medicine Universitas Padjadjaran
}

\begin{abstract}
Background: Diabetes mellitus (DM) is a common disease found all over the world, including Indonesia. The DM often found in pediatric patients is DM Type 1. The DM patients with uncontrolled blood glucose will likely suffer multiple organ damage, most notably to the kidneys, eyes, heart, and nerves. To help monitor blood glucose levels, lab checkups such as fasting blood glucose, 2 hours postprandial, and Hemoglobin A1C (HbA1C) levels are done. The aim of this study was to determine the profile of blood glucose and HbA1C in pediatric patients with DM Type 1.

Methods: The study was held in August to October 2014, using descriptive method and cross sectional design. Data were obtained from 28 medical records of DM Type 1 patients in the Department of Child Health at Dr. Hasan Sadikin General Hospital. The variables of this study were blood glucose level and HbA1 in three consecutive examinations. The collected data was presented in tables.

Results: The patients were 19 female and 9 male, most of the patients aged between 11-15 years old. Data reported that on first, second, and third examination, most subjects had both fasting blood glucose and 2 hours postprandial blood glucose levels over $180 \mathrm{mg} / \mathrm{dl}$. On first and second HbA1c checkup, most subjects had values over $10 \%$, and on third checkup had results ranging from 8 to $9.9 \%$.

Conclusions: Most patients are girls and aged between 11-15 years old. The most have uncontrolled blood glucoselevel and $\mathrm{HbA1c}$ levels.
\end{abstract}

Keywords: Blood glucose levels, $\mathrm{HbA1C}$, diabetes mellitus type 1

\section{Introduction}

Diabetes Mellitus (DM) is a common disease found all over the world. Currently, approximately $2.8 \%$ of the world's population has DM, and study estimated, it will reach $4.4 \%$ by $2030,{ }^{1}$ including DM Type 1 patients. According to the Basic Health Reserach (Riset Kesehatan Dasar/Riskesdas), in Indonesia there was an increase of DM patients from $1.1 \%$ by 2007 to $2.1 \%$ by 2013 .

The DM that develops in children is DM Type 1 . The DM Type 1 is caused by an autoimmune process, resulting in destruction of pancreatic beta cells and thus, the decrease of insulin production. This abnormality in pancreas is usually permanent. DM Type 1 commonly develops in children aged 7-15 years old, although it can occur at all ages. ${ }^{2}$ Most parents are unaware that their children suffers DM Type 1, mainly due to lack of knowledge about DM Type $1 .^{3}$

The typical clinical presentation of DM Type 1 is polyuria, polydipsia, polyphagia and progressive loss of body weight despite adequate if not excessive eating. Mostly, DM Type 1 patients are diagnosed after suffering complications such as diabetic ketoacidosis (DKA). ${ }^{4}$ DM patients with uncontrolled blood glucose levels will suffer in various organ-kidneys, eyes, heart and neurologicdysfunctions. ${ }^{5}$ The hyperglycemic state cause functional alterations and target of organ damage. Fasting blood glucose (FBG), 2 hours post prandial (2hPP) blood glucose, and Hemoglobin A1c (HbA1C) are laboratory parameter to monitor the blood glucose levels. Blood glucose and HbA1c monitoring

Correspondence: Anisha Sefina Priatna, Faculty of Medicine, Universitas Padjadjaran, Jalan Raya Bandung-Sumedang Km.21, Jatinangor, Sumedang, Indonesia, Phone: +62 8121455786 Email: anisha_sefina@yahoo.com 
are essential in preventing complications especially DKA. HbA1C measurement provides the overview of average blood glucose levels within eight to twelve weeks duration.

Some advantages of HbA1C test are; that it can be done anytime and it does not need any specific preparation such as fasting. HbA1C and blood glucose measurement results are used to diagnose DM. Diagnosis of DM when HbA1C levels $\geq 6.5 \%$. Internal Committee and American Diabetes Association in 2010 recommended that $\mathrm{HbA1C}$ measurement, can be used for screening in individuals with high risk for diabetes. ${ }^{8}$ The aim of this study was to determine the profile of blood glucose level and $\mathrm{HbA1C}$ in DM type 1 pediatric patients.

\section{Methods}

This descriptive study was carried out using medical records of DM Type 1 patients in Dr. Hasan Sadikin General Hospital. All subjects that fulfilled the inclusion criteria, that was having the HbA1c measurements in three consecutive from August to October 2014. This study had been approved by the Health Research Ethics Committee Dr. Hasan Sadikin General Hospital Bandung.

From 42 subjects, 14 subjects did not meet the inclusion criteria, and the other 28 subjects that fulfilled the inclusion criteria were studied further. Data that was used as variables were characteristics (age, gender), fasting blood glucose measurement, 2 hours post prandial blood glucose (2hPPBG) measurement, and HbA1c measurement. The collected data were presented in tables.

From 20 subjects, in the first measurement, 13 subjects had blood glucose levels over 180 $\mathrm{mg} / \mathrm{dl}$. In the second measurement, majority of the subjects were still inside the over 180 $\mathrm{mg} / \mathrm{dl}$ category, even though there were 3 subjects decrease. Note that in the second measurement, 1 subject had no result. In the third measurement, 9 subjects were in the over $180 \mathrm{mg} / \mathrm{dl}$ category, which showed 1 subject decrease compared to the second measurement. However, the number of subjects were the same ( 9 subjects) in the less than $180 \mathrm{mg} / \mathrm{dl}$ category, and there were two subjects without results.

From 28 subjects, in the first measurement, the majority of subjects had HbA1c levels above $10 \%$, which categorized them in poor metabolic control. In the second measurement, most subjects were still in the poor metabolic control category, with 1 subject decrease. In the third measurement, there was a large decrease in the poor metabolic control category, as much as 6 subjects, making most subjects in this measurement, as much as 13 subjects, categorized in moderate metabolic control.

\section{Results}

This study discovered that from 28 patients, most of them were female and between 11 to 15 years old (Table 1 ).

From 20 subjects, in the first measurement, most subjects (14 subjects), had fasting blood glucose levels over $180 \mathrm{mg} / \mathrm{dl}$. In the second measurement, most subjects still had fasting blood glucose levels over $180 \mathrm{mg} / \mathrm{dl}$, but it were 3 subjects less. In the third measurement, majority of the subjects still had FBG levels over $180 \mathrm{mg} / \mathrm{dl}$, and there were 2 subjects increase compared to the second measurement.

From 20 subjects, in the first measurement, 13 subjects had blood glucose levels over 180 $\mathrm{mg} / \mathrm{dl}$. In the second measurement, majority of the subjects were still inside the over 180 $\mathrm{mg} / \mathrm{dl}$ category, even though there were 3 subjects decrease. Note that in the second measurement, 1 subject had no result. In the third measurement, 9 subjects were in the over $180 \mathrm{mg} / \mathrm{dl}$ category, which showed 1 subject decrease compared to the second measurement. However, the number of subjects were the same ( 9 subjects) in the less than $180 \mathrm{mg} / \mathrm{dl}$ category, and there were two subjects without results.

From 28 subjects, in the first measurement, the majority of subjects had HbA1c levels above $10 \%$, which categorized them in poor metabolic control. In the second measurement, most subjects were still in the poor metabolic control category, with 1 subject decrease. In the third measurement, there was a large decrease in the poor metabolic control category, as

Table 1 Subject Characteristics

\begin{tabular}{lc}
\hline \multicolumn{1}{c}{ Patient Profile } & n \\
\hline Gender & \\
Male & 9 \\
Female & 19 \\
Age & \\
$<5$ years old & 3 \\
6-10 years old & 7 \\
11-15 years old & 14 \\
$>15$ years old & 4 \\
\hline
\end{tabular}


Table 2 Fasting Blood Glucose Levels

\begin{tabular}{lccc}
\hline \multirow{2}{*}{ Fasting Blood Glucose } & 1st measurement & 2nd measurement & 3rd measurement \\
\cline { 2 - 5 } & $\mathrm{n}$ & $\mathrm{n}$ & $\mathrm{n}$ \\
\hline$<126 \mathrm{mg} / \mathrm{dl}$ & 5 & 6 & 6 \\
$126-140 \mathrm{mg} / \mathrm{dl}$ & 0 & 0 & 0 \\
$140-180 \mathrm{mg} / \mathrm{dl}$ & 1 & 2 & 1 \\
$>180 \mathrm{mg} / \mathrm{dl}$ & 14 & 11 & 13 \\
Total & 20 & 20 & 20 \\
\hline
\end{tabular}

Table 3 Two Hours Post Prandial Blood Glucose Levels

\begin{tabular}{lccc}
\hline \multirow{2}{*}{ 2hPPBG* $^{*}$} & 1st measurement & 2nd measurement & 3rd measurement \\
\cline { 2 - 4 } & $\mathrm{n}$ & $\mathrm{n}$ & $\mathrm{n}$ \\
\hline$<180 \mathrm{mg} / \mathrm{dl}$ & 7 & 9 & 9 \\
$>=180 \mathrm{mg} / \mathrm{dl}$ & 13 & 10 & 9 \\
No results & 0 & 1 & 2 \\
Total & 20 & 20 & 20 \\
\hline
\end{tabular}

Note: *2 Hours Post Prandial Blood Glucose Levels

much as 6 subjects, making most subjects in this measurement, as much as 13 subjects, categorized in moderate metabolic control.

\section{Discussions}

In this study, most DM Type 1 subjects were girls, and most DM Type 1 subjects were aged between 11-15 years old. This was concordant to the general subjects characteristics in the study conducted by Maahs et al. ${ }^{9}$ This results were also well-suited to the theory mentioning the onset of DM Type 1 increase in puberty and more common in girls. This was due to the involvement of estrogen, or genes regulated by estrogen, such as interleukin-6. The increasing number of cases in puberty were parallel to the increasing number of exposure to infectious agents in the beginning of school days, and also the increasing hormonal activity in puberty, which worked antagonist to insulin. ${ }^{2}$

For the fasting and 2 hours post prandial blood glucose levels, which could be seen in Table 2 and Table 3, there were decreasing trend in the first, second, and third measurements. This meant that subjects had satisfactory control of their blood glucose levels. The HbA1c measurement, which could be seen in table 4 , showed that there were also a decreasing trend in the first, second, and third measurements. A maintained HbA1c levels showed the subjects' had a satisfactory metabolic control of their disease, and therefore will hopefully also decrease, delay, or

Table 4 HbA1c Levels

\begin{tabular}{lccc}
\hline \multirow{2}{*}{ HbA1c $^{*}$} & 1st measurement & 2nd measurement & 3rd measurement \\
\cline { 2 - 4 } & $\mathrm{n}$ & $\mathrm{n}$ & $\mathrm{n}$ \\
\hline$<6 \%$ & 2 & 2 & 1 \\
$6-7.9 \%$ & 7 & 6 & 7 \\
$8-9.9 \%$ & 5 & 7 & 13 \\
$>=10 \%$ & 14 & 13 & 7 \\
Total & 28 & 28 & 28 \\
\hline
\end{tabular}

Note: *Hemoglobin A1c 
even avoid microvascular complications such as retinopathy and nephropathy. ${ }^{2} \mathrm{~A}$ continuous blood glucose monitoring could benefit in controlling blood glucose and HbA1c levels in DM type 1 patients. ${ }^{10}$ This monitoring, most importantly and fundamentally, is needed to be done by the subjects and their families. The components that need to be monitored are insulin dose, subjects' physical activity, and subjects' diet. ${ }^{2}$ If there were any discrepancies between the subject's blood glucose and HbA1c levels, the cause should be searched and determined. Some causes include patients' compliance in insulin injection, the manner of insulin injection itself, and subjects' diet program.

There were limitations that might interfere with the results of this study. Firstly, the study was done in a very short period of time, making the number of subjects retrieved very limited and maybe not ideal. Secondly, errors due to incomplete data and mistakes in data writing made it more difficult analyzing and processing the data.

Conclusions of this study are most subjects were girls and aged between 11-15 years old. Most subjects with uncontrolled blood glucose and HbA1c levels decreased in every following measurement. However, most subjects were still in the above normal category. This showed that blood glucose and HbA1c control in most subjects were slowly getting satisfactory.

Recommendations of this study are more proper, organized, complete and maybe computerized data writing could ease the data collecting, and also further study needed to be done to determine the factors influencing the blood glucose and HbA1c levels in DM Type 1 patients. In addition, subjects are expected to routinely control and monitor their blood glucose and $\mathrm{HbA} 1 \mathrm{c}$ levels, and giving education to the subjects and their families about their disease how to control their blood glucose might be beneficial.

\section{References}

1. Wild S, Roglic G, Green A, Sicree R, King H. Global prevalence of diabetes estimates for the year 2000 and projections for 2030. Diabetes Care. 2004;27(5):1047-53.

2. Alemzadeh R, Ali O. Diabetes mellitus. In: Kliegman RM, editors. Kliegman: nelson textbook of pediatrics. $19^{\text {th }}$ ed. Philadelphia: Elsevier-Saunders; 2011. p. 1968-93.

3. Aman Pulungan, Herqutanto. Diabetes melitus tipe 1: "penyakit baru" yang akan makin akrab dengan kita. Maj Kedokt Indon. 2009;59(10):455-458.

4. American Diabetes Associaton. Standards of medical care in diabetes-2014. Diabetes Care. 2014;37(Suppl1):S14-80.

5. American Diabetes Associaton. Diagnosis and classification of diabetes mellitus. Diabetes Care. 2010;33(Suppl1):S62-69.

6. Day A. HbA1c and diagnosis of diabetes: the test has finally come of age. Ann Clin Biochem. 2012;49(1):7-8.

7. Cohen RM, Haggerty S, Herman WH. HbA1c for the diagnosis of diabetes and prediabetes: is it time for a mid-course correction?. J Clin Endocrinol Metab. 2010;95(12):5203-6.

8. Alqahtani N, Khan WA, Alhumaidi MH, Ahmed YA. Use of glycated hemoglobin in diagnosis of diabetes mellitus and pre-diabetes and role of fasting plasma glucose, oral glucose tolerance test. Int J Prev Med.2013;4(9):1025-9.

9. Maahs DM, West NA, Lawrence JM, Mayer-Davis EJ. Epidemiology of type 1 diabetes. Endocrinol Metab Clin North Am. 2010;39(3):481-97.

10. Battelino T, Phillip $M$, Bratina N, Nimri $\mathrm{R}$, Oskarsson $\mathrm{P}$, Bolinder J. Effect of continuous glucose monitoring on hypoglycemia in type 1 diabetes. Diabetes Care. 2011;34(4):795-800. 